Research Article

\title{
Static Game Models and Applications Based on Market Supervision and Compliance Management of P2P Platform
}

\author{
Sulin Pang $\mathbb{D}^{1,2,3}$ Junkun Yang, ${ }^{1,3}$ Rongzhou Li, ${ }^{4}$ and Jun Cao ${ }^{2}$ \\ ${ }^{1}$ Institute of Finance Engineering in School of Management, School of Emergency Management, Jinan University, \\ Guangzhou 510632, Guangdong, China \\ ${ }^{2}$ School of Emergency Industry/School of Information Engineering, Guangzhou Pearl-River College of Vocational Technology, \\ Huizhou 516131, Guangdong, China \\ ${ }^{3}$ Guangdong Emergency Technology Research Center of Risk Evaluation and Prewarning on Public Network Security, \\ Guangzhou 510632, Guangdong, China \\ ${ }^{4}$ Macau Chinese Bank, Macao 999078, China \\ Correspondence should be addressed to Sulin Pang; pangsulin@jnu.edu.cn
}

Received 31 August 2020; Revised 15 September 2020; Accepted 3 October 2020; Published 26 October 2020

Academic Editor: Maojun Zhang

Copyright (c) 2020 Sulin Pang et al. This is an open access article distributed under the Creative Commons Attribution License, which permits unrestricted use, distribution, and reproduction in any medium, provided the original work is properly cited.

\begin{abstract}
This article focuses on the two-party static game between market supervisory organization and peer-to-peer (P2P) lending platform. Considering 4 game modes with both "strong supervision" and "weak supervision" of market supervisory organization and "compliance management" and "noncompliance management" of P2P lending platform, the paper establishes a static game model between P2P lending platform and market supervisory organization and solves the market equilibrium solutions. Based on income, cost, disguised cost, and fine of $\mathrm{P} 2 \mathrm{P}$ lending platform and income, cost, and reward of market supervisory organization, it discusses conditional strategies that P2P lending platform selects "compliance management" or "noncompliance management" and that market supervisory organization selects "strong supervision" or "weak supervision," respectively. Furthermore, the relevant influencing factors are analyzed which come from 18 P2P lending platforms in Guangdong Province of China, and the conclusions were in good agreement with the actual market. The research has scientific guiding significance.
\end{abstract}

\section{Introduction}

In China, peer-to-peer (P2P) platform loans began to emerge in 2013 and have been running for more than ten years. P2P lending platform is an important innovative business model, which has been widely concerned by the government, industry, and researchers [1]. In 2016, China's Internet finance ushered in the "first year of supervision." As an important part of Internet finance, the P2P lending platform naturally became the focus of supervision. 2017 is the "first year of compliance" of China's online lending, and 2018 is the "first year of filing" of China's online lending. From this, we can see that China has made up its mind to rectify the $\mathrm{P} 2 \mathrm{P}$ lending platform. At present, China's various regulatory policies have been issued intensively and a series of regulatory measures have been introduced by the state and local governments, which have put a brake on the rapid development of Internet finance. Therefore, it is very important for market supervisory organizations to supervise and manage the P2P lending platform and the platform's compliance. It is in this historical and social context that this paper puts forward the game model and application of compliance management between supervisory organizations and $\mathrm{P} 2 \mathrm{P}$ lending platforms, so it has very important practical significance.

At present, the biggest problem of P2P network lending platform is information asymmetry and moral hazard. The way to solve this problem is to develop a conceptual model through the process of lending and adopt completely different credit auditing methods, which can make the information flow in P2P network lending more frequent and transparent, reveal the problem of information asymmetry, 
and reduce moral hazard [2]. The rise of P2P lending platform has created new opportunities for social lending platform, but because of information asymmetry, many thunderstorms have also occurred. From the data of KIVA, it can be seen that the moral hazard is always high because the P2P lending platform does not know enough about borrower's loan conditions and makes decisions based on discernment bias [3]. We can use financial intermediation theory to analyze the role of $\mathrm{P} 2 \mathrm{P}$ lending platform. The functions of financial intermediaries and banks are different. P2P lending platform does not create funds and does not carry out risk and term conversion. Therefore, P2P lending platform needs to ensure that financial intermediaries are not affected by the principal-agent problem and to effectively solve the inherent moral hazard of modern financial intermediaries through incentive mechanism [4]. In order to solve the problem of large traffic sharing between Internet service and ISP in P2P sharing systems, if the fluid model is combined with a simple ISP traffic model, the influencing factors of P2P lending platform cannot be accurately evaluated. However, the peer-to-peer selection mechanism based on proximity can avoid the increase of Internet service traffic in the $\mathrm{P} 2 \mathrm{P}$ sharing system and improve the information sharing efficiency of the P2P platform [5]. In the sharing system, the lack of motivation to share knowledge and the problem of free customers may lead to shorter service life of the P2P platform. But, by building subsystems in the P2P lending platform and stimulating these subsystems and sharing systems separately, synthesizing the loan, sharing the platform, P2P incentive, bank incentive, and so on, into the sharing society, it can help to prolong the life cycle of the P2P lending platform [6]. China's P2P lending platform has maintained an increase in total capital since its operation, but serious problems have been encountered in fraud and liquidity [7]. Perceived risk is very important to reveal the moral hazard of the P2P lending platform. In view of the dimension of perceived risk, it is found that physical capital variables, investors' perspective, and platform characteristic variables have a direct impact on perceived risk dimension, but the impact of social environment on perceived risk is not significant [8]. Using the public data set of PPDAI on the P2P lending platform, the information of social media is fused and the credit scoring model of decision tree is constructed. From the credit scoring model and classification rules, it can be concluded that loan information, social media information, and credit information are important factors to predict default [9]. By mining the text data of borrower's motivation and then using classifier technology to analyze and identify borrower's motivation, the data set of social loan platform KIVA can verify the validity of this method [10]. The joint and several liability loan contracts are obtained by the lender using the group loan plan. Under the condition of asymmetric information, the lender can form the self-choice with the borrower by inducing the endogenous group. At this time, there will be a game phenomenon between the P2P lending platform and the multiparty [11].

In recent years, supply chain finance has been widely used on P2P lending platform. Retailers and manufacturers must consider the financial decision of online P2P lending platform (such as service interest rate) when making business decisions [12]. The limited information provided by the $\mathrm{P} 2 \mathrm{P}$ lending platform is usually not enough for the lender to determine whether the borrower is trustworthy and able to repay the loan. Therefore, it is necessary to study the impact of the communication between the lender and the borrower on the financing results and loan performance, which can help the understanding and role of information disclosure, social influence, information quality, and trust in the P2P lending platform in online economic communication [13]. By mining data on the Internet, the loan data of large P2P lending platforms can be combined with the existing data of popular social media websites and the default probability of borrowers can be predicted [14]. Internet-based information systems (ISs) have realized various forms of collective intelligence, action, and resources (such as open source software, innovative markets, crowdsourcing, and crowdfunding).

In the field of crowdfunding, the Internet-enabled P2P lending system (IP2PL) has become a disruptive technology that has impacted financial services, business capitalization strategies, and personal and community development [15]. Although the borrower who failed in the P2P lending platform cannot repay all the loans, it can recover a certain amount of the loan. Analysis of 40,901 P2P lending platforms found that the probability of default was high [16]. P2P lending platforms and lenders are very concerned about predicting whether borrowers will be default on repayments. Because the data type of P2P network lending platform is complex, it is difficult to quantify and analyze unstructured information such as text, so loan default prediction is facing new challenges in P2P [17]. The role of information disclosure in reducing market efficiency has been the subject of extensive research. Although cost-free, voluntary, and verifiable disclosure is unlikely to be a reliable source of information, information disclosure can increase transparent understanding of market efficiency [18]. Using the agent connection rate, degree, comparative ratio of available nodes, centrality, network density, network efficiency, and edge loading capacity, the system risk of P2P loan market is modeled and analyzed from the perspective of complex network. It is found that the relationship between loanborrow network topology and default loan is significant [19]. When we study the relationship between text-related factors and the probability of successful financing and default of peer-to-peer loans of two leading European platforms, we find that text-related factors can hardly predict the default probability of $\mathrm{P} 2 \mathrm{P}$ loans of the two platforms if capital is obtained as a condition [20]. The P2P online lending market brings together noninstitutional borrowers and lenders. In a typical lending market, borrowers have to show their projects and lenders decide on the terms on which they are prepared to provide the required capital. However, since many borrowings are not secured by collateral, the most important task is to assess the borrower's credit [21]. In the absence of hard and quantifiable bank data, investors are unable to translate existing information into appropriate market activities, thus threatening the sustainability of this 
new lending concept [21]. Through the analysis of more than 200,000 loan application materials by using the Language Query and Word Statistics (LIWC) software, it is found that there is a positive correlation between the written narrative related to personal financial situation and the success of loan [22].

This paper considers for the first time that there are two kinds of supervision methods for market supervision, namely, "strong supervision" and "weak supervision." There are two different operation modes of "compliance management" and "noncompliance management" in P2P platform. It puts forward four game modes between market supervision department and $\mathrm{P} 2 \mathrm{P}$ platform: (strong supervision, compliance management), (strong supervision, noncompliance management, (weak supervision, compliance management), and (weak supervision, noncompliance management). The paper is structured as follows. Section 2 establishes the payment matrix of the game between the P2P platform and the supervisory organization through the assumption of premise and variable. Then, under strong supervision and weak supervision, the static game models of P2P platform and supervisory organization are established, respectively. At the same time, the static game models of $\mathrm{P} 2 \mathrm{P}$ platform and supervisory organization are established under the conditions of compliance and noncompliance, respectively. Section 3 is from different perspectives to analyze the various related behavioral factors of the supervision organizations and the P2P lending platforms. These factors will affect the probability of the P2P lending platforms choosing compliance or noncompliance, as well as the probability of the third-party supervision organizations choosing strong supervision and weak supervision. Section 4 is to collect 236 data from the normal operation platform of Guangdong Province at the end of 2018 and 404 of the problem platform, that is, the total platform size is 640 , and carry out case analysis of relevant influencing factors. Finally, Section 5 concludes this work.

\section{Static Game between Both Market Supervision Organizations and P2P Platforms}

According to the second section, the risk of default on the P2P platform is very large and the market supervision department needs to supervise the platform. However, due to the market supervision, there are two methods of supervision: "strong supervision" and "weak supervision." The low supervision cost is low, and the strong supervision cost is high. The platform will also have two different operation strategies: "compliance management" and "noncompliance management." Compliance operation is difficult, and noncompliance operation is simple. To this end, this paper studies four game modes between market supervision and P2P platforms: (strong supervision, compliance management), (strong supervision, noncompliance management), (weak supervision, compliance management), and (weak supervision, noncompliance management), and we find the equilibrium solution and discuss the impact of various variables on the P2P online lending platform and market supervision.
2.1. Premise Hypothesis and Variable Hypothesis. For the $\mathrm{P} 2 \mathrm{P}$ platform, if it chooses to operate in compliance, the normal revenue of its compliance operation is $R_{1}$ and if it chooses to operate in noncompliance, the additional income (i.e., speculative income) it receives is $R_{2}$. For a compliant P2P platform, the unit operating cost it needs to pay is $C_{1}$. The "unit" in this article can refer to a P2P platform. Assume that the market supervision agency implements strong supervision costs, per unit of input $C_{2}$, and weakly supervised costs of implementation, per unit of input $C_{3}$; then, there is $C_{3}<C_{2}$. If we consider the existence of moral hazard and choose the platform of irregular operation, in order to avoid supervision, we will pay a certain camouflage cost, assuming that the unit camouflage cost is $C_{4}$; then, there is $C_{4}<C_{1}$. Obviously, once the platform chooses to operate irregularly, for speculative borrowers in the $\mathrm{P} 2 \mathrm{P}$ market, in order to obtain the loan of the P2P platform, they will set a certain false project return rate, pour into the irregularly operated P2P platform, and wait for the loan by promising to give the $\mathrm{P} 2 \mathrm{P}$ platform a certain profit rebate. Then, they will run away to escape debts immediately. In reality, even the compliant P2P platform does not fully guarantee the lender's financial security. A noncompliant P2P platform may not necessarily result in the loss of funds of the lender. In order to study the consistency of the premise, this paper only considers a situation where if the $\mathrm{P} 2 \mathrm{P}$ platform chooses to operate in noncompliance, it will result in the loss of the lender's funds, assuming that the unit's financial loss is $a$. In the process of research, $a$ is regarded as the loss to the whole society, that is, the loss of public interest, including the loss of reputation of the $\mathrm{P} 2 \mathrm{P}$ platform, the decrease of investors' trust in the $\mathrm{P} 2 \mathrm{P}$ market, and various invisible losses in the $\mathrm{P} 2 \mathrm{P}$ market. This paper regards the supervision organization as the representative of the public interest to bear these explicit and implicit losses.

Assume that under the strong supervision of the supervision organization, once the noncompliant $\mathrm{P} 2 \mathrm{P}$ platform is discovered, it will be exposed and punished, assuming the unit fine as $A$. It is also assumed that the supervision organization will not process the kickback of the opportunity investors obtained from the noncompliant P2P platform (because it cannot be investigated), but the fines for fines will be owned by the supervision organization. Due to the noncompliant P2P platform, once it is detected by the supervision organization, it will be exposed. It is assumed that the profit of the negative exposure of the $\mathrm{P} 2 \mathrm{P}$ platform by the supervision organization is $R_{3}$. Since the P2P platform is negatively exposed due to noncompliance, its reputation will obviously be seriously negatively affected. Therefore, the earnings of the P2P platform after being negatively exposed will be lower than the normal earnings of compliance operation, that is, $R_{3}<R_{1}$. This paper records $r=R_{3}-R_{1}<0$, where $r$ is a negative value indicating the reputation loss of the P2P platform after being negatively exposed.

Under the weak supervision of the supervision organization, the $\mathrm{P} 2 \mathrm{P}$ platform that chooses noncompliant operation has invested in the camouflage cost, so the supervision organization is misled. At this time, instead of punishing the $\mathrm{P} 2 \mathrm{P}$ platform, it encourages the $\mathrm{P} 2 \mathrm{P}$ platform, assuming that 
the incentive cost of the supervision organization is $E$. Further assume that the market size of the P2P platform is $L$; the probability of choosing a compliant $\mathrm{P} 2 \mathrm{P}$ platform is $p=(0 \leq p \leq 1)$, and the probability of choosing a noncompliant $\mathrm{P} 2 \mathrm{P}$ platform is $1-p$. Another meaning of $p$ is that the bigger the $p$, the greater the probability that the $\mathrm{P} 2 \mathrm{P}$ platform chooses to operate in compliance; this also indicates that the $\mathrm{P} 2 \mathrm{P}$ platform intends to choose compliance management. Also, the smaller the $p$, the smaller the probability that the $\mathrm{P} 2 \mathrm{P}$ platform chooses to operate in compliance. That is, the $\mathrm{P} 2 \mathrm{P}$ platform's intention is to choose noncompliant operations. In the $\mathrm{P} 2 \mathrm{P}$ platform market, the probability that the supervision organization adopts strong supervision is $q=(0 \leq q \leq 1)$ and the probability of adopting weak supervision is $1-q$. Another meaning of $q$ is that the bigger the $q$, the greater the probability that the supervision organization chooses strong supervision; this also indicates that the supervision organization will choose to supervise. Also, the smaller the $q$, the smaller the probability that the supervision organization chooses strong supervision. That is, the supervision organization' intention is to choose weak supervision.

2.2. Establish a Static Game Payment Matrix. Under the assumption that the market size of the P2P platform is $L$, we have the following cases:

(1) When the supervision organization conducts strong supervision, it needs to pay the supervision cost as $C_{2} L$. If the $\mathrm{P} 2 \mathrm{P}$ lending platform chooses to operate in compliance, the supervision organization needs to issue incentive $E$ to the P2P lending platform. At this time, the benefits of P2P platform include three parts: one is the normal revenue $R_{1}$ obtained by compliance operation; the other is the audit cost $C_{1} L$ for the compliance operation; and the third is the incentive $E$ issued by the supervision organization. If the P2P lending platform chooses to operate in noncompliance, the expected benefits of the supervision organization consists of three parts: one is to pay the supervisory cost $C_{2} L$; the other is the loss $a L$ to the entire P2P online loan market when there are noncompliant operators in the market; and the third is to impose a fine $A L$ on the platform. At this point, the benefit of the noncompliant P2P online lending platform is composed of four parts: one is that it can receive the rebate delivery $R_{2}$ from the low-quality borrower; the other is that the normal return $R_{3}$ is obtained by the platform after being investigated and punished; the third is the fine $A L$ that needs to be handed over to the supervision organization; and the fourth is to pay a certain camouflage cost for the platform as $C_{4} L$.

(2) When the supervision organization conducts weak supervision, if the P2P lending platform chooses to operate in compliance, the supervision cost paid by the supervision organization is $C_{3} L$ and the incentive issued to the P2P platform of the compliance operation is $E$. At this point, the benefit of the P2P lending platform that operates in compliance has three parts: one is the normal income $R_{1}$ obtained by the compliance operation; the other is the audit cost $C_{1} L$ for the compliance operation; the third is the incentive $E$ issued by the supervision organization. If the P2P lending platform chooses to operate in noncompliance, the weak supervision cost that the supervision organization needs to pay is $C_{3} L$ and the loss caused by the noncompliant operation of the P2P market is aL. Since the noncompliant P2P lending platform will also invest a certain amount of camouflage costs, the supervision organization still needs to issue incentive $E$ to these noncompliant P2P lending platforms. In addition, the benefit of the noncompliant P2P lending platform consists of four parts: one is the normal return $R_{1}$ obtained during normal operation, the other is that it may receive rebate $R_{2}$ from low-quality borrowers; the third is to obtain the incentive $E$ issued by the supervision organization; and the fourth is the need to pay a certain camouflage cost as $C_{4} L$. Based on this, we establish a static game payment matrix, as shown in Table 1.

\subsection{Static Game Model}

2.3.1. Supervision Organization Expectation Return Model Based on Static Game. This section calculates the probability $p$ of $\mathrm{P} 2 \mathrm{P}$ online lending platform selection compliance operation. When $p$ is given, from the perspective of the supervision organization, according to the payment matrix Table 1 and when the supervision organization chooses strong supervision $q=1$, according to the game theory $[23,24]$, the expected return $E(p, 1)$ can be expressed as

$$
\begin{aligned}
E(p, 1) & =p\left(-C_{2} L-E\right)+(1-p)\left(A L-a L-C_{2} L\right) \\
& =\left(A+p-a-C_{2}\right) L-A L p .
\end{aligned}
$$

When the supervision organization chooses weak supervision $q=0$, the expected return $E(p, 0)$ can be expressed as

$$
\begin{aligned}
E(p, 0) & =p\left(-C_{3} L-E\right)+(1-p)\left(-C_{2} L-a L-E\right) \\
& =-C_{3} L-a L-E+L p .
\end{aligned}
$$

However, from the perspective of the P2P lending platform, it does not want the supervision organization to guess how it should deal with market supervision, let alone to make its own decisions to conduct compliance or noncompliance operations to be found out. Therefore, from the perspective of the expected income of the supervision organization, whether it is strong supervision or weak supervision, it follows the principle of no arbitrage in the equilibrium state. There is no difference in expected returns. Therefore, according to the principle of no arbitrage in the equilibrium state of the static game, the equilibrium conditions of the market at this time are

$$
E(p, 1)=E(p, 0) \text {. }
$$


TABLE 1: Payment matrix of the game between the P2P platform and the supervision organization.

\begin{tabular}{lcr}
\hline Market supervision organization & P2P lending platform \\
& Compliance management $(p)$ & Noncompliance management $(1-p)$ \\
\hline Strong supervision $(q)$ & $\left(-C_{2} L-E, R_{1}+E-C_{1} L\right)$ & $\left(A L-a L-C_{2} L, R_{2}+R_{3}-A L-C_{4} L\right)$ \\
Weak supervision $(1-q)$ & $\left(-C_{3} L-E, R_{1}+E-C_{1} L\right)$ & $\left(-C_{3} L-a L-E, R_{1}+R_{2}+E-C_{4} L\right)$ \\
\hline
\end{tabular}

Find the equilibrium solution as follows:

$$
p^{*}=\frac{\left(C_{3}-C_{2}+A\right) L+E}{A L}
$$

The $p^{*}$ of equation (4) is the probability of $\mathrm{P} 2 \mathrm{P}$ online lending platform selecting compliance operation under equilibrium state. Because $0 \leq p \leq 1$, we have

$$
0 \leq E \leq\left(C_{2}-C_{3}\right) L
$$

Equation (5) indicates that incentive $E$ is issued by the supervision organization using the cost difference of the intensity of supervision. The following discusses the probability $p$ of the $\mathrm{P} 2 \mathrm{P}$ lending platform to choose compliance management:

(1) If the P2P lending platform chooses the probability of compliance operation $p<\left(\left(\left(C_{3}-C_{2}+A\right) L+E\right) / A L\right)$, it shows that the P2P lending platform actually chooses noncompliant operations. The precondition for the P2P lending platform to choose noncompliant operations is that the income from choosing noncompliant operations is greater than the benefit from selecting compliance operations, so we have the following:

(i) If $\quad C_{2}-C_{3}<((A L+E) / L)$, then $A L-a L-C_{2} L>C_{3} L-a L-E$. At this point, the supervision organization chooses strong supervision. This shows that when the difference between strong supervision cost and weak supervision cost $C_{2}-C_{3}$ is less than $(A L+E) / L$, that is, when the difference between strong supervision cost and weak supervision cost is not too big, the supervision organization chooses strong supervision. On the one hand, it is beneficial to the supervision organization to invest in the P2P market, and on the other hand, it can supervise the noncompliant $\mathrm{P} 2 \mathrm{P}$ platform to meet the standard operation.

(ii) If $\quad C_{2}-C_{3}<((A L+E) / L)$, then $A L-a L-C_{2} L>C_{3} L-a L-E$. At this point, the supervision organization chooses weak supervision. This is because when $C_{2}-C_{3}>((A L+E) / L)$, the strong supervision cost invested by the supervision organization is very different from the weak supervision cost. If the supervision organization chooses strong supervision, it will invest a large cost. In order to save costs, the supervision organization will be more willing to choose weak supervision for the P2P market. (iii) If $\quad C_{2}-C_{3}<((A L+E) / L), \quad$ then $A L-a L-C_{2} L=C_{3} L-a L-E$. At this point, the supervision organization will choose strong supervision or weak supervision according to the actual operation of the P2P market.

(2) If the P2P lending platform chooses the probability of compliance operation $p>\left(\left(\left(C_{3}-C_{2} A\right) L+E\right) / A L\right)$, it indicates that the $\mathrm{P} 2 \mathrm{P}$ lending platform chooses to operate in compliance. Because $C_{3}<C_{2},-C_{3} L-E>C_{2} L-E$; that is, the supervision organization chooses the benefits of weak supervision to be greater than the benefits of strong supervision. At this point, the supervision organization must choose weak supervision. That is to say, when the $\mathrm{P} 2 \mathrm{P}$ lending platform chooses to operate in compliance, the supervision organization will choose weak supervision to reduce the supervision cost.

(3) In the equilibrium state, the probability of P2P lending platform selecting compliance operation is $p^{*}\left(\left(\left(C_{3}-C_{2} A\right) L+E\right) / A L\right)$; then, the supervision organization will choose strong supervision or weak supervision according to the actual operation of the market.

2.3.2. P2P Lending Platform Expectation Return Model Based on Static Game. In this section, we calculate the probability $q$ of selecting strong supervision by the supervision organization. When given $q$, from the perspective of $\mathrm{P} 2 \mathrm{P}$ lending platform, according to the payment matrix in Table 1, the expected return $E(1, q)$ of the P2P lending platform to select the compliance operation $p=1$ can be expressed as

$$
\begin{aligned}
E(1, q) & =q\left(R_{1}-C_{1} L+E\right)+(1-q)\left(R_{1}-C_{1} L+E\right) \\
& =R_{1}+E-C_{1} L .
\end{aligned}
$$

The expected return $E(0, q)$ of the P2P lending platform to select noncompliant business $p=0$ can be expressed as

$$
\begin{aligned}
E(0, q) & =q\left(R_{2}+R_{3}-A L-C_{4} L\right)+(1-q)\left(R_{2}+R_{1}+E-C_{4} L\right) \\
& =\left(R_{3}-A L-R_{1}-E\right) q+R_{2}+R_{1}+E-C_{4} L .
\end{aligned}
$$

Similarly, from the point of view of the supervision organization, they do not want $\mathrm{P} 2 \mathrm{P}$ lending platforms to guess what kind of supervisory strategies they will choose; that is, they do not want to make strong or weak supervisory decisions to be discovered by the platform, so the expected benefits of the supervision organization for P2P lending platforms in compliance and noncompliance are no different. Therefore, according to the principle of no arbitrage 
in the equilibrium state of the static game, the equilibrium conditions of the market are as follows:

$$
E(1, q)=E(0, q)
$$

Solving equation (6) can obtain the market equilibrium solution as follows:

$$
q^{*}=\frac{C_{4} L-C_{1} L-R_{2}}{R_{3}-R_{1}-A L-E} .
$$

The $q^{*}$ of equation (9) is the probability that the P2P online lending platform chooses to operate in compliance under equilibrium.

We know $1 \leq q \leq 1, \quad$ so $C_{4} L-C_{1} L-R_{2} \leq R_{3}-R_{1}-A L-E$. The following discussion of the probability $q$ of the supervision organization to choose strong supervision:

(1) If the supervision organization chooses the probability of strong supervision $q<\left(\left(C_{4} L-C_{1} L-R_{2}\right) /\left(R_{3}-R_{1}-A L-E\right)\right), \quad$ it means that the supervision organization actually chose weak supervision. Because $C_{4}<C_{1}$, $R_{2}+R_{1}+E-C_{4} L>R_{1}+E-C_{1} L$; this shows that the $\mathrm{P} 2 \mathrm{P}$ lending platform has chosen noncompliant operations. Therefore, when the supervision organization conducts weak supervision on the market, the P2P lending platform will choose noncompliant operations.

(2) If the supervision organization chooses the probability of strong supervision $q>\left(\left(C_{4} L-C_{1} L-R_{2}\right) /\left(R_{3}-R_{1}-A L-E\right)\right), \quad$ it means that the supervision organization actually chose strong supervision.

(i) When $E>R_{2}+\left(R_{3}-R_{1}\right)+\left(C_{1}-C_{4}\right) L-A L$, there is $R_{1}+E-C_{1} L>R_{2}+R_{3}-A L-C_{4} L$. This shows that when the supervision organization's reward $E$ for the P2P lending platform exceeds $R_{2}+\left(R_{3}+R_{1}\right)+\left(C_{1}-C_{4}\right) L-A L$ or when the supervision organization's incentive for the P2P lending platform is sufficiently large, the $\mathrm{P} 2 \mathrm{P}$ lending platform will choose to operate in compliance.

(ii) When $E<R_{2}+\left(R_{3}-R_{1}\right)+\left(C_{1}-C_{4}\right) L-A L$, there is $R_{1}+E-C_{1} L<R_{2}+R_{3}-C_{4} L-A L$. This shows that when the supervision organization's reward $E$ for the $\mathrm{P} 2 \mathrm{P}$ lending platform is less than $R_{2}+\left(R_{3}-R_{1}\right)+\left(C_{1}-C_{4}\right) L-A L$ or when the supervision organization's incentive for the $\mathrm{P} 2 \mathrm{P}$ lending platform is not strong enough, the P2P lending platform will choose noncompliant operations.

(iii) When $E=R_{2}+\left(R_{3}-R_{1}\right)+\left(C_{1}-C_{4}\right) L-A L$, there is $R_{1}+E-C_{1} L=R_{2}+R_{3}-C_{4} L-A L$; at this point, the $\mathrm{P} 2 \mathrm{P}$ lending platform will choose to operate in compliance or noncompliance according to the actual situation of market supervision.

(3) In equilibrium, the probability that the supervision organization chooses strong supervision is $q^{*}=\left(\left(C_{4} L-C_{1} L-R_{2}\right) /\left(R_{3}-R_{1}-A L-E\right)\right)$; at this point, the P2P lending platform will arbitrarily choose to operate in compliance or not.

Therefore, the equilibrium state of the game is $\left\{\left(p^{*}, 1-p^{*}\right)\left(q^{*}, 1-q^{*}\right)\right\} ; \quad$ that is, $\left\{\left(\left(\left(\left(C_{3}-C_{2}+A\right) L+\right.\right.\right.\right.$ $\left.E) / A L), 1-\left(\left(\left(C_{3}-C_{2}+A\right) L+E\right) / A L\right)\right)\left(\left(\left(C_{4} L-C_{1} L+R_{2}\right) /\right.\right.$ $\left.\left(R_{3}-R_{1}-A L-E\right)\right), 1-\left(\left(C_{4} L-C_{1} L+R_{2}\right) /\left(R_{3}-R_{1}-A L-\right.\right.$ $E)))\}$. The P2P lending platform conducts compliance operations with a probability greater than $p^{*}=\left(\left(\left(C_{3}-C_{2}+\right.\right.\right.$ $A) L+E)(A L)$, and the supervision organization conducts strong supervision with a probability greater than $q^{*}=\left(\left(C_{4} L-C_{1} L-R_{2}\right) /\left(R_{3}-R_{1}-A L-E\right)\right)$.

\section{Analysis of the Influence of Game Model Parameter Changes on Equilibrium Points}

According to the probability under the equilibrium state, we analyze how the behavior factors of participants influence the probability of strong supervision of the supervision organizations and the probability of the P2P lending platform choosing to operate in compliance.

3.1. Analysis of the Impact of Platform Compliance Operating Probability $p^{*}$ on Other Behavioral Factors in Equilibrium State. When the game is in equilibrium, the probability expression $p^{*}=\left(\left(\left(C_{3}-C_{2}+A\right) L+E\right) / A L\right)$ of the $\mathrm{P} 2 \mathrm{P}$ platform choosing the compliance strategy is analyzed. From this expression, it can be seen that there are five variables that affect the probability of $\mathrm{P} 2 \mathrm{P}$ lending platform selecting compliance operation, as follows:

(1) The relationship between the $p^{*}$ and the unit cost $C_{2}$ of strong supervision by the supervision organization

Because $\left(\partial p^{*} / \partial C_{2}\right)=-(1 / A)<0$, when other conditions are constant, equilibrium state $p^{*}$ and unit cost $C_{2}$ of strong supervision by supervision organization are monotonously decreasing. That is, when the unit cost of the supervised organization's strong supervision increases, the probability that the $\mathrm{P} 2 \mathrm{P}$ lending platform chooses the compliance management strategy will decrease. It may be because when the cost of the supervision organization keeps rising, the supervision organization will reduce the supervision because of the high cost, which indirectly leads to that the probability of choosing a compliant business strategy for the P2P lending platform will decrease. Therefore, we need to reduce 
or save the unit cost of supervision by financial institutions as much as possible, which can indirectly increase the probability of the P2P lending platform choosing the compliance strategy, so as to better select those participants with better credit level, which is conducive to the development of the industry.

(2) The relationship between the $p^{*}$ and the unit penalty $A$ payment of the $\mathrm{P} 2 \mathrm{P}$ lending platform after detection by supervision organizations

Because $\left(\partial p^{*} / \partial A\right)=\left(\left(\left(C_{2}-C_{3}\right) L-E\right) / A^{2} L\right) \geq 0$, when other conditions are constant, the relationship between the equilibrium state $p^{*}$ and the unit penalty $A$ of a P2P lending platform detected by the supervision organization is in a monotonous increase. That is, when the unit penalty $A$ paid by the P2P lending platform increases, the probability of the $\mathrm{P} 2 \mathrm{P}$ lending platform selecting a compliant business strategy will increase. As the unit fine increases, the $\mathrm{P} 2 \mathrm{P}$ lending platform may evade the amount of the fine to be larger than its expected return. Therefore, for the supervision organization, the fines can be appropriately increased to increase the probability of compliance operation of the $\mathrm{P} 2 \mathrm{P}$ lending platform, and at the same time, it is also a kind of protection for high-quality borrowers.

(3) The relationship between the $p^{*}$ and the unit cost $C_{3}$ of weak supervision by the supervision organization

Because $\left(\partial p^{*} / \partial C_{3}\right)=-(1 / A)>0$, when other conditions are constant, equilibrium state $p^{*}$ and unit cost $C_{3}$ of weak supervision by supervision organization are monotonously increasing. That is to say, when the unit cost of weak supervision increases, the probability of the $\mathrm{P} 2 \mathrm{P}$ lending platform choosing the compliance management strategy will increase. Maybe, when the weak supervision cost of the supervision organization increases, the scope and breadth of supervision organization will also increase, which indirectly leads to that the probability of the P2P lending platform choosing the compliance strategy will increase. Therefore, we need to increase the breadth of supervision as much as possible without changing the intensity of supervision, which can indirectly increase the probability of P2P lending platform choosing the compliance management strategy, so as to better select those participants with better credit level, which is conducive to the development of the industry.

(4) The relationship between the $p^{*}$ and the incentive $E$ obtained when the P2P lending platform is operating in compliance

Because $\left(\partial p^{*} / \partial E\right)=(1 / A L)>0$, when other conditions are constant, the relationship between the equilibrium state $p^{*}$ and the incentive $E$ obtained when the P2P lending platform is operating in compliance is monotonously increasing. That is to say, when the incentive for the compliance operation of P2P lending platform increases, the probability of selecting the compliance operation strategy of P2P lending platform will increase, because when the incentive increases, the $\mathrm{P} 2 \mathrm{P}$ lending platform can increase its expected revenue. So for the supervision organization, the incentive intensity can be increased appropriately to increase the probability of the compliance operation of the P2P lending platform.

(5) Relationship between $p^{*}$ and market size $L$

Because $\left(\partial p^{*} / \partial L\right)=\left(1 / A L^{2}\right)<0$, when other conditions are constant, the relationship between the equilibrium state $p^{*}$ and the market size $L$ is monotonously decreasing. That is, the larger the P2P market is, the lower the probability that the P2P lending platform will choose a compliant business strategy. It may be because when the P2P market continues to rise, the supervision organization will reduce the supervision or noncompliance platform because of the high cost. The probability of institutional investigations is reduced, which indirectly leads to a lower probability that the P2P lending platform will choose a compliant business strategy. Therefore, we need to maintain the market size as much as possible within a reasonable range, which is neither too large and difficult to supervise nor can it be too small to inhibit the healthy development of the platform. It can indirectly increase the probability of selecting a compliance management strategy for the $\mathrm{P} 2 \mathrm{P}$ lending platform. It will be better to select those participants with better credits, which will benefit the development of the industry.

3.2. Analysis of the Influence of Strong Supervision Probability of Supervision Organizations on Other Behavioral Factors in Equilibrium State. When the equilibrium state of the game is reached, the supervision organization selects the probability expression $q^{*}=\left(\left(C_{4} L-C_{1} L-R_{2}\right) /\left(R_{3}-\right.\right.$ $\left.R_{1}-A L-E\right)$ ) of the strong supervision for analysis. From the expression, it can be known that there are seven variables that will affect the probability that the supervision organization chooses strong supervision, as follows:

(1) The relationship between the $q^{*}$ and the P2P lending platform to select the unit cost $C_{3}$ of the compliance management

Because $\left(\partial p^{*} / \partial C_{1}\right)=-\left(L /\left(R_{2}-R_{1}-A L-E\right)\right)>0$, when other conditions are constant, the relationship between the equilibrium state $q^{*} Q$ and the unit cost $C_{1}$ of the P2P lending platform to select the compliance operation is monotonously increasing. That is, when the unit cost of the $\mathrm{P} 2 \mathrm{P}$ lending platform choosing to operate in compliance increases, the probability of strong supervision by the supervision organization will increase. Because when carrying out compliance management, the P2P lending platform will pay a certain amount of manpower cost and financial cost to carry out information audit of 
borrowers, information audit of loan projects, etc., while some platforms may have a fluke mentality in order to ensure their benefits with the increase of payment cost and then adopt irregular operation, so that the supervision organization can carry out the supervision. It will increase the probability of its supervision.

(2) The relationship between the $q^{*}$ and the P2P lending platform to select the unit camouflage cost $C_{4}$ of noncompliant management

Because $\left(\partial p^{*} / \partial C_{1}\right)=-\left(L /\left(R_{2}-R_{1}-A L-E\right)\right)>0$, when other conditions are constant, the relationship between the equilibrium state $q^{*}$ and the unit camouflage cost $C_{4}$ of the $\mathrm{P} 2 \mathrm{P}$ lending platform to select noncompliant operations is monotonously decreasing. That is, when the $\mathrm{P} 2 \mathrm{P}$ lending platform chooses the unit camouflage cost $C_{4}$ of the noncompliant management to increase, the probability of the supervision organization performing strong supervision will decrease. It may be because of the noncompliance management, as the cost of camouflage continues to increase, the supervision organization mistakenly believes that there are more compliance platforms in the market, so it tends to adopt weak supervision in the next supervision process.

(3) The relationship between the $q^{*}$ and the extra income $R_{2}$ obtained by the platform due to noncompliance

Because $\left(\partial p^{*} / \partial R_{2}\right)=-\left(L /\left(R_{3}-R_{1}-A L-E\right)\right)>0$, when other conditions are constant, the relationship between the equilibrium state $q^{*}$ and the additional benefit $R_{2}$ obtained by the platform due to noncompliant management is monotonously increasing. That is, when the additional income $R_{2}$ obtained by the platform due to noncompliant management increases, the probability of the supervision organization performing strong supervision increases. Because this kind of income due to noncompliance is an abnormal income, if this phenomenon is generated in a large area, it will have a very adverse impact on the industry and the stability of the financial order will be affected. Therefore, the supervision organization will increase the probability of strong supervision to prevent this phenomenon from happening.

(4) The relationship between $q^{*}$ and the unit fine $A$ payment of P2P lending platform after it was found out by the supervision organization because it did not operate in compliance

Because $\quad\left(\partial q^{*} / \partial A\right)=\left(\left(L\left(C_{4} L-C_{1} L-R_{2}\right)\right)\right.$ / $\left.\left(R_{3}-R_{1}-A L-E\right)^{2}\right) \leq 0$, when other conditions are constant, the relationship between equilibrium state $q^{*}$ and unit fine $A$ paid by the supervision organization after it was found out that the P2P lending platform did not operate in compliance is monotonously decreasing. That is, the greater the number of unit fines imposed by the supervision organization on the $\mathrm{P} 2 \mathrm{P}$ lending platform, the less likely the supervision organization will conduct strong supervision. Because the unit fines increase, the P2P lending platform will choose to operate in compliance to avoid paying fines, so the supervision organization will reduce its probability of supervision. Therefore, we can impose appropriate fines on platforms that do not conduct compliance operations, which can not only ensure the supervision of the supervision organization but also enable the P2P lending platform to choose the strategy of compliance management and promote self-discipline.

(5) The relationship between $q^{*}$ and the revenue $R_{3}$ of $\mathrm{P} 2 \mathrm{P}$ lending platform which is punished by the supervision organization after it is found out that no compliance management is carried out and normal revenue $R_{1}$ of $\mathrm{P} 2 \mathrm{P}$ lending platform compliance management

Here, we will make $r=R_{3}-R_{1}<0$; $r$ is used because the lending platform has not been found by the supervision organizations to operate in compliance, and the loss is caused by the decline in reputation of information after it is made public in the market.

Because $C_{4}<C_{1}, \quad\left(\partial q^{*} / \partial r\right)=\left(L\left(C_{4} L-C_{1} L-R_{2}\right) /\right.$ $\left.\left(R_{3}-R_{1}-A L-E\right)^{2}\right) \leq 0$, so when other conditions are constant, the relationship between equilibrium state $q^{*}$ and reputation loss $r$ of $\mathrm{P} 2 \mathrm{P}$ lending platform is monotonously decreasing after being detected by supervision organizations because of noncompliance operation. That is, the greater the reputation loss of the P2P lending platform, the lower the probability that the supervision organization will conduct strong supervision. Therefore, for the P2P lending platform, industry self-discipline should be strengthened to prevent excessive dependence on the supervision organization. For supervision organizations, the information sharing system should be strengthened and social supervision should be assisted to promote effective competition and survival of the fittest in the industry.

(6) Relationship between $q^{*}$ and market size $L$

Because $\left(\partial q^{*} / \partial L\right)=\left(\left(C_{4}-C_{1}\right)\left(R_{2}-R_{2}-E\right) /\left(R_{3}-\right.\right.$ $\left.\left.R_{1}-A L-E\right)^{2}\right)>0$, when other conditions are constant, the relationship between the equilibrium state $q^{*}$ and the market size $L$ of the P2P lending platform is monotonously increasing. That is, the larger the size of the entire $\mathrm{P} 2 \mathrm{P}$ market, the greater the probability that the supervision organization will conduct strong supervision. Therefore, when the platform for noncompliance is growing, there will be more and more platforms for noncompliance, the potential harm to the society will be greater and greater, and the financial order will become increasingly unstable. Therefore, the supervision organization will increase the probability of 
supervision to protect the financial security and rights of the participants. Therefore, as a supervision organization, it can reduce the losses caused by noncompliant operating platforms and maintain the stability of financial order through strong supervision.

(7) The relationship between the $q^{*}$ and the incentive $E$ issued by the supervision organization

\begin{abstract}
Because $\left(\partial q^{*} / \partial E\right)=\left(\left(C_{4} L-C_{1} L-R_{2}\right) /\right.$ $\left.\left(R_{3}-R_{1}-A L-E\right)^{2}\right)<0$, when other conditions are constant, the relationship between the equilibrium state $q^{*}$ and the incentive $E$ issued by the supervision organization is monotonously decreasing. That is, the greater the incentives issued, the more the supervision policy tends to be supervised by means of market regulation and platform self-discipline, that is, by issuing greater incentives to promote competition within the industry; that is, the probability of adopting weak supervision will increase.
\end{abstract}

\section{Model Application and Case Analysis}

4.1. Data Collections. In 2018, Guangdong Province ranked first in the number of P2P lending platforms in China and ranked among the top three in terms of online loan balance (Guangdong, Beijing, Shanghai). By the end of 2018, there were 236 platforms in normal operation in Guangdong Province and 404 problem platforms, with a total platform size of 640 (See https://m.wdzj.com); that is, the market size of Guangdong Province was $\mathrm{L}=640$. In 2018, the total transaction volume of China's Guangdong P2P lending platform was 270 billion. The income source of the general platform is directly proportional to the transaction volume, which is approximately $1 \%-10 \%$ of the transaction volume, including handling fees and management fees. And, the total volume in 2018 is $10 \%$ less than that in the previous year. We can regard these reductions as the reputation loss of those platforms that violate the rules after exposure, that is, $r=$ $R_{3}-R_{1}=-270000$ million yuan. According to the actual situation, the cost of normal operation of a medium-sized $\mathrm{P} 2 \mathrm{P}$ lending platform including at least the construction cost, operating cost, and customer acquisition cost of the website is about 2 million per year; that is, $C_{1}=200$ million yuan, assuming that the camouflage cost is one tenth, that is, $C_{4}=200,000$ yuan. According to the publicity of the special fund (financial services) support project for promoting economic development in Guangdong Province in 2018, a total of 60 million special funds will be issued, involving a total of 20 million financial innovations; that is, the total incentives obtained during compliance operations will be $E=20$ million yuan. According to the penalty notice for the $\mathrm{P} 2 \mathrm{P}$-related violation platform, most of the fines are between 10,000 and 50,000 yuan, except for some platforms that involve a large amount of money. For example, China Anhui Juyun Technology Co., Ltd. was suspected of violating the regulations and was imposed an administrative penalty of
40,000 yuan by the Industrial and Commercial Quality Supervision Bureau of Bengbu City. Shenzhen Jinhai loan financial service company was fined 12,000 yuan, and Shenyang Haifo Xingmin Investment Co., Ltd. was fined 10,000 yuan by the Shuangyashan Market Supervision Bureau. Based on the above information, combined with the actual situation in Guangdong Province of China, we assume that the unit cost of the weak supervision by the supervision organization is between 0 and 10000 yuan of $C_{3}$. The unit cost of strong supervision by the supervision organization is 50000 and 60000 yuan of $C_{2}$. The unit penalty paid by the P2P lending platform after being detected by the supervision organization is $A=30,000$ yuan and $R_{2}=10$ million yuan.

\subsection{Analysis of Related Factors}

4.2.1. Impact of $C_{2}$ and $C_{3}$ on the Probability $p^{*}$ of Platform Selection for Compliant Operation. Assuming that the incentive $E=2000$ issued by the supervisory authority, platform market size $L=640$, and penalty after exposure of noncompliant operation $A=3$, we consider that when the unit cost of strong supervision is $C_{2}=5,5.25,5.5,5.75$, and 6 , the unit costs of weak supervision of supervision institutions are $C_{3}=0,0.25,0.5,0.75$, and 1 , the impact of $C_{2}$ and $C_{3}$ on the probability $p^{*}$ of platform selection compliance operation is analyzed. According to formula (4), the corresponding value of $p^{*}$ can be calculated, as shown in Table 2 .

When $E=2000, L=640$, and $A=3$, the expression $p^{*}=$ $\left(\left(C_{3}-C_{2}+A L+E\right) / A L\right)$ of the platform selection compliance management probability when substituting $C_{2}=5$ and $C_{3}=0$ into the equilibrium state can be found at this time $p^{*}=0.38$ (keep 2 decimal places). Other values are calculated using this logic. In order to visualize the table, the value of $C_{3}$ is separately $0,0.25,0.5,0.75$, and 1 , as shown in Figure 1.

As shown in Figure 1, the unit cost $C_{2}$ of the platform selection compliance operation probability $p^{*}$ and the supervision organization for strong supervision is monotonously decreasing. That is, when the unit cost of the supervision by the supervision organization increases, the probability of the $\mathrm{P} 2 \mathrm{P}$ lending platform selecting the compliance management strategy will decrease. The unit cost $C_{3}$ of weak supervision with the supervision organization is monotonously increasing. That is, when the unit cost of the weak supervision by the supervision organization increases, the probability of the P2P lending platform selecting the compliance management strategy will increase.

4.2.2. Impact of $E$ and $A$ on the Probability $p^{*}$ of Platform Selection for Compliance Operation. Suppose that the unit cost of weak supervision is $C_{3}=0.25$, the market size of platform is $L=640$, and the unit cost of strong supervision is $C_{2}=6.25$, we analyze the impact of $E$ and $A$ on the probability $p^{*}$ of compliance operation of the platform when the incentive given by the supervision organization is $E=2000$, 
TABLE 2: The influence of $C_{2}$ and $C_{3}$ on the probability $p^{*}$ of the platform to choose compliance management (take $E=2000, L=640$, and $A=3)$.

\begin{tabular}{|c|c|c|c|c|c|}
\hline$p^{*}$ & $C_{2}=5$ & $C_{2}=5.25$ & $C_{2}=5.5$ & $C_{2}=5.75$ & $C_{2}=6$ \\
\hline$C_{3}=0$ & 0.38 & 0.29 & 0.21 & 0.13 & 0.04 \\
\hline$C_{3}=0.25$ & 0.46 & 0.38 & 0.29 & 0.21 & 0.13 \\
\hline$C_{3}=0.5$ & 0.54 & 0.46 & 0.38 & 0.29 & 0.21 \\
\hline$C_{3}=0.75$ & 0.63 & 0.54 & 0.46 & 0.38 & 0.29 \\
\hline$C_{3}=1$ & 0.71 & 0.63 & 0.54 & 0.46 & 0.38 \\
\hline
\end{tabular}

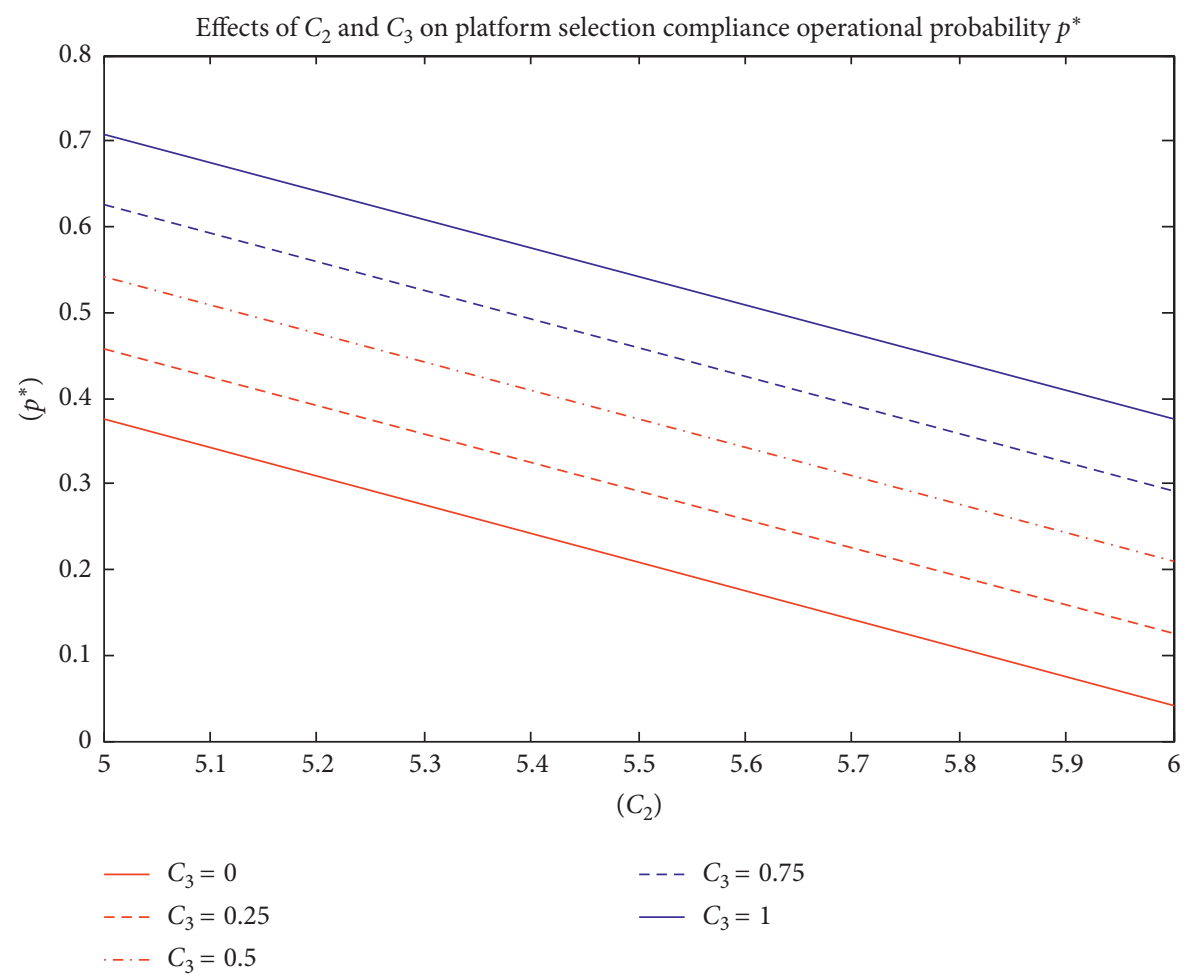

FIgURE 1: The influence of $C_{2}$ and $C_{3}$ on the probability $p^{*}$ of the platform to choose compliance management.

TABle 3: The impact of $E$ and $A$ on the probability $p^{*}$ of platform selection compliance management (take $C_{3}=0.25, L=640$, and $\left.C_{2}=6.25\right)$.

\begin{tabular}{lccccc}
\hline$p^{*}$ & $E=2000$ & $E=2200$ & $E=2400$ & $E=2600$ & 0.35 \\
\hline$A=3$ & 0.04 & 0.15 & 0.25 & 0.52 & 0.46 \\
$A=4$ & 0.28 & 0.36 & 0.44 & 0.61 & 0.59 \\
$A=5$ & 0.43 & 0.49 & 0.55 & 0.68 & 0.68 \\
$A=6$ & 0.52 & 0.57 & 0.63 & 0.72 & 0.73 \\
$A=7$ & 0.59 & 0.63 & 0.68 & 0.77 \\
\hline
\end{tabular}

$E=2000,2200,2400,2600$, and 2800, as well respectively, and the penalty $A=3,4,5,6$, and 7 after the nonconforming operation is found and exposed. According to formula (4), the corresponding value of $p^{*}$ can be calculated, as shown in Table 3.

When $C_{3}=0.25, L=640$, and $C_{2}=6.25$, the expression $p^{*}=\left(\left(C_{3}-C_{2}+A L+E\right) / A L\right)$ of the platform selection compliance management probability when substituting $E=$
2000 and $A=3$ into the equilibrium state can be found at this point, $p^{*}=0.04$ (keep 2 decimal places). Other values are calculated using this logic. In order to visualize the table, the value of $E$ is separately taken as 2000, 2200, 2400, 2600, and 2800, as shown in Figure 2.

It is known from Figure 2 that the relationship between the equilibrium state $p^{*}$ and the unit penalty $A$ paid by the $\mathrm{P} 2 \mathrm{P}$ lending platform after being detected by the supervision 


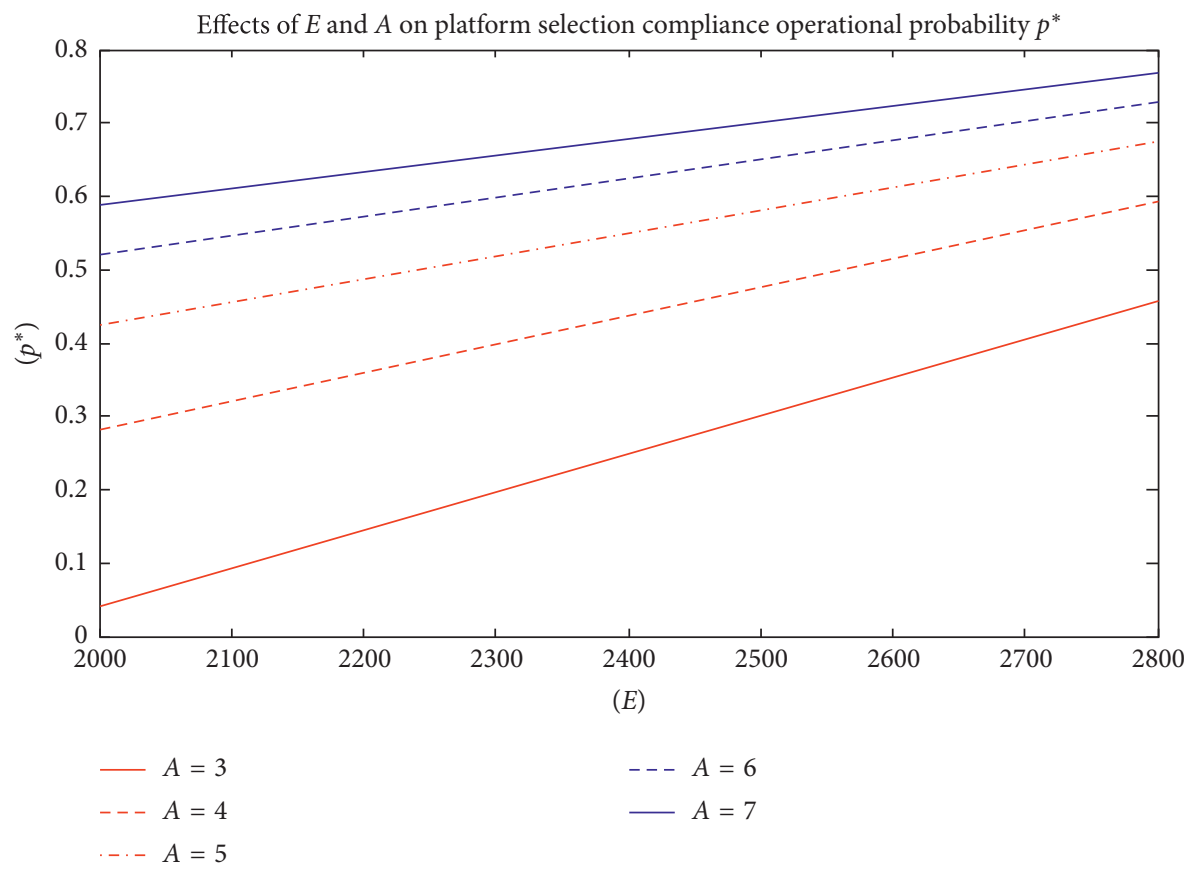

Figure 2: The influence of $E$ and $A$ on the probability $p^{*}$ of the platform to choose compliance management.

TABLE 4: The impact of $L$ on the probability $p^{*}$ of the platform to choose compliance management (take $C_{3}=0.25, E=1800, A=4$, and $\left.C_{2}=6.25\right)$.

\begin{tabular}{llllll}
\hline$L$ & 500 & 625 & 714 & 789 & 849 \\
$p^{*}$ & 0.40 & 0.22 & 0.13 & 0.07 & 0.03 \\
\hline
\end{tabular}

organization is monotonously increasing. That is, when the unit penalty $A$ paid by the P2P lending platform increases, the probability of selecting a compliance management strategy for the P2P lending platform will increase. The relationship between the equilibrium state $p^{*}$ and the incentive $E$ obtained during the P2P platform's compliance management is monotonously increasing. That is, when the incentive E obtained during the P2P platform's compliance operation increases, the probability of the $\mathrm{P} 2 \mathrm{P}$ lending platform selecting the compliance management strategy increases.

4.2.3. Impact of L on the Probability $p^{*}$ of Platform Selection for Compliant Operation. Assuming that the supervision organization is weak in supervising unit cost $C_{3}=0.25$, incentives issued by supervisory bodies is $E=1800$, penalty after exposure of noncompliant operation is $A=4$, and supervision institutions strengthen supervision of unit cost $C_{2}=6.25$, we consider the impact on the probability $p^{*}$ that the platform choices the compliance operation when the market size of the platform is $L=500$, $625,714,789$, and 849 , respectively. According to formula
(4), the corresponding value of $p^{*}$ can be calculated, as shown in Table 4.

When $C_{3}=0.25, E=1800, A=4$, and $C_{2}=6.25$, the expression $p^{*}=\left(\left(C_{3}-C_{2}+A L+E\right) / A L\right)$ of the platform selection compliance management probability when substituting $L=600$ into the equilibrium state can be found at this point, $p^{*}=0.40$ (keep 2 decimal places). Other values are calculated using this logic. In order to visualize the table, the value of $L$ is separately taken as 600,850,1100, 1350, and 1600, as shown in Figure 3.

It can be seen from Figure 3 that the relationship between the equilibrium state $p^{*}$ and the market size $L$ is monotonously decreasing; that is, the larger the P2P market size, the lower the probability that the $\mathrm{P} 2 \mathrm{P}$ lending platform selects the compliance management strategy.

4.2.4. Influence of $C_{4}$ and $C_{1}$ on the Probability $q^{*}$ of Strong Supervision by Supervision Organizations. Assuming that incentives from supervisory agencies $E=2000$, platform market size $L=640$, penalty after exposure of noncompliant operation $A=3$, additional revenue from platform noncompliant operation $R_{2}=1000$, and reputation loss of illegal 


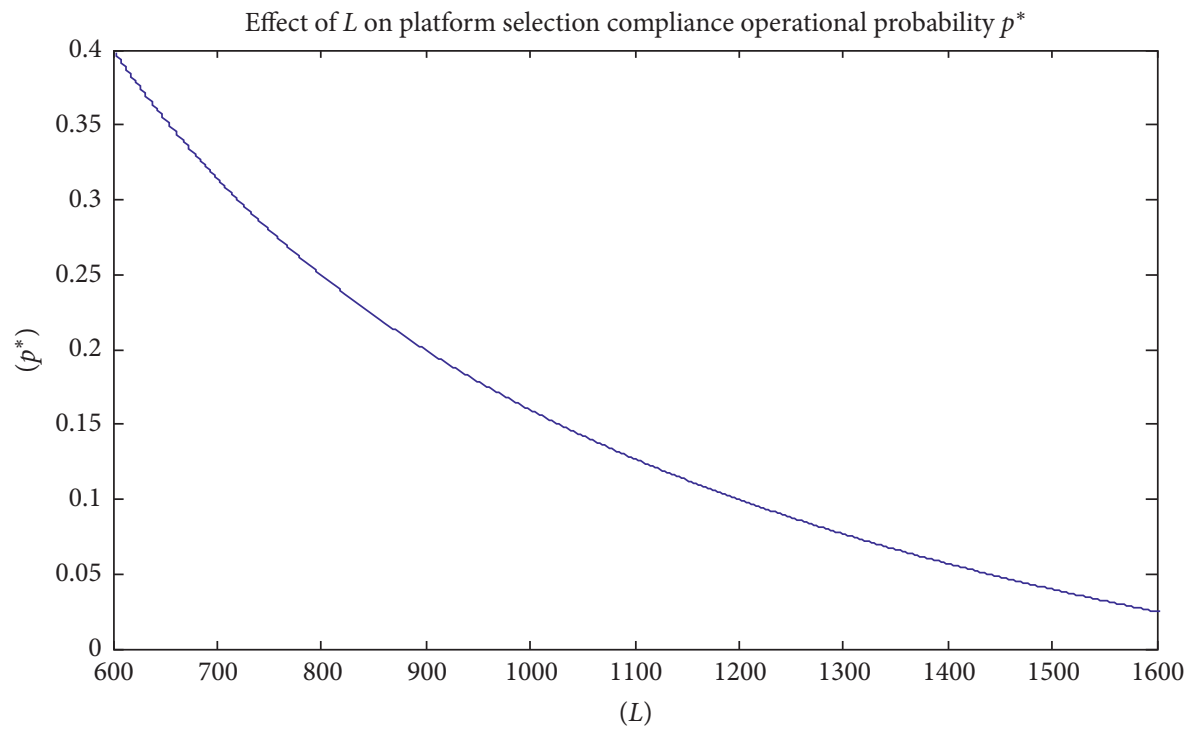

FIgURE 3: The influence of $L$ on the probability $p^{*}$ of the platform to choose compliance management.

TABLE 5: The influence of $C_{4}$ and $C_{1}$ on the probability $q^{*}$ of strong supervision by the supervision organization (take $E=2000, L=640$, $A=3, R_{2}=1000$, and $\left.R_{3}-R_{1}=-270000\right)$.

\begin{tabular}{lccccc}
\hline$q^{*}$ & $C_{4}=20$ & $C_{4}=30$ & $C_{4}=40$ & $C_{4}=50$ & 0.35 \\
\hline$C_{1}=200$ & 0.42 & 0.40 & 0.38 & 0.41 & 0.33 \\
$C_{1}=225$ & 0.48 & 0.46 & 0.44 & 0.47 & 0.39 \\
$C_{1}=250$ & 0.54 & 0.52 & 0.49 & 0.53 & 0.45 \\
$C_{1}=275$ & 0.60 & 0.58 & 0.55 & 0.59 & 0.51 \\
$C_{1}=300$ & 0.66 & 0.63 & 0.61 & 0.56 \\
\hline
\end{tabular}

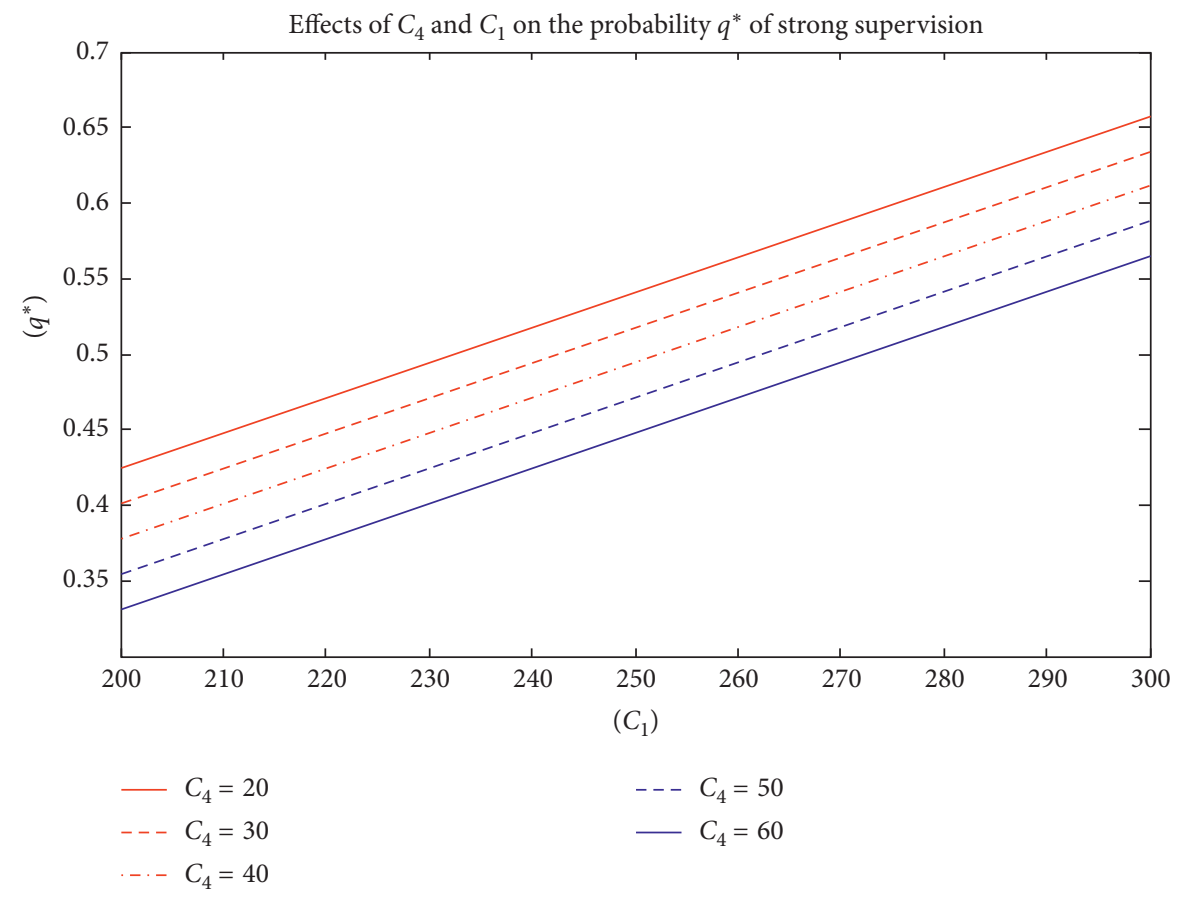

FIgURE 4: The influence of $C_{1}$ and $C_{4}$ on the probability $q^{*}$ of strong supervision by the supervision organization. 
platform after being exposed $R_{3}-R_{1}=-270000$, we consider that the camouflage costs are $C_{4}=20,30,40,50$, and 60 , the influence of $C_{4}$ and $C_{1}$ on the probability $q^{*}$ of strong supervision by the supervision organization is analyzed. According to formula (4), the corresponding value of $q^{*}$ can be calculated, as shown in Table 5 .

When $\quad E=2000, \quad L=640, \quad A=3, \quad R_{2}=1000$, $R_{3}-R_{1}=-270000, C_{1}=200$, and $C_{4}=20$ are substituted for equilibrium state, the expression $p^{*}=\left(\left(C_{3}-C_{2}+A L+\right.\right.$ $\left.E) /\left(R_{3}-R_{1}-A L-E\right)\right)$ of strong supervision probability is determined by the supervision organization, which can be found at this point, $q^{*}=0.42$ (keep 2 decimal places). Other values are calculated using this logic. In order to visualize the table, the value of $C_{4}$ is separately taken as $20,30,40,50$, and 60, as shown in Figure 4:

It is known from Figure 4 that when the P2P lending platform chooses the unit camouflage cost $C_{4}$ of noncompliant operation to increase, the probability $q^{*}$ of the supervision organization to conduct strong supervision will decrease. When the unit cost of a P2P lending platform chooses to operate in compliance, the probability of a supervision organization exercising strong supervision will increase.

4.2.5. Influence of $R_{2}$ and $r\left(r=R_{3}-R_{1}\right)$ on the Probability $q^{*}$ of Strong Supervision by the Supervision Organization. Assuming that incentives from supervisory agencies $E=2000$, platform market size $L=640$, penalty after exposure of noncompliant operation $A=3$, camouflage cost in noncompliance operation $C_{4}=30$, and platform compliance operating unit cost $C_{1}=250$, we consider that when the platform is noncompliant, the additional income is $R_{2}=1000,1050,1100,1150$, and 1200 and the reputation loss of the illegal platform after being exposed $R_{3}-R_{1}=-270000,-275000,-280000,-285000$, and -290000 , the influence of $R_{2}$ and $R_{3}-R_{1}$ on the probability $q^{*}$ of strong supervision by supervision organization is analyzed. According to formula (4), the corresponding value of $q^{*}$ can be calculated, as shown in Table 6 .

When $E=2000, L=640, A=3, C_{1}=250, C_{4}=30$, $R_{2}=1000$, and $R_{3}-R_{1}=-270000$ are substituted for equilibrium state, the expression $q^{*}=\left(\left(C_{3}-C_{2}+A L+E\right) /\left(R_{3}-R_{1}-A L-E\right)\right)$ of strong supervision probability is determined by supervision organization, which can be found at this point, $q^{*}=0.5177$ (keep 4 decimal places). Other values are calculated using this logic. In order to visualize the table, the value of $R_{3}-R_{1}$ is separately taken as $-270000,-275000,280000,-285000$, and -290000, as shown in Figure 5.

It is known from Figure 5 that the greater the reputation loss of the P2P lending platform, the lower the probability $q^{*}$ of the supervision organization to conduct strong supervision. When the platform increases the additional income $R_{2}$ due to noncompliance, the probability of strong supervision by the supervision organization increases.

4.2.6. Influence of $L$ and $A$ on the Probability $q^{*}$ of Strong Supervision by the Supervision Organization. Assuming that incentives from supervisory agencies $E=2000$, additional revenue from platform noncompliant operation $R_{2}=1150$, reputation loss of illegal platform after being exposed $R_{3}-R_{1}=-280000$, camouflage cost in noncompliance operation $C_{4}=30$, and platform compliance operating unit cost $C_{1}=250$, we consider that when the market size of the platform is $L=600,620,640,660$, and 680, respectively, and the fine $a=3,4,5,6$, and 7 after the nonconforming operation is found and exposed, we analyze the impact of $L$ and $a$ on the probability $q^{*}$ of strong supervision by the supervision organization. According to formula (4), the corresponding value of $q^{*}$ can be calculated, as shown in Table 7.

When $E=2000, \quad R_{2}=1150, \quad R_{3}-R_{1}=-270000$, $C_{1}=250, C_{4}=30, L=600$, and $A=3$ are substituted for equilibrium state, the expression $q^{*}=\left(\left(C_{3}-C_{2}+A L+E\right) /\left(R_{3}-R_{1}-A L-E\right)\right)$ of strong supervision probability is determined by the supervision organization, which can be found at this point, $q^{*}=0.4692$ (keep 4 decimal places). Other values are calculated using this logic. In order to visualize the table, the value of $A$ is separately taken as 3, 4, 5, 6, and 7, as shown in Figure 6.

It is known from Figure 6 that the larger the size of the entire P2P market, the greater the probability that the supervision organization will conduct strong supervision. The greater the number of unit fines imposed by the supervision organization on the $\mathrm{P} 2 \mathrm{P}$ lending platform, the less likely the supervision organization will conduct strong supervision.

4.2.7. Influence of $E$ on the Probability $q^{*}$ of Strong Supervision by the Supervision Organization. Assuming that the additional revenue from noncompliance operation of the platform is $R_{2}=1000$, reputation loss of illegal platform after being exposed $R_{3}-R_{1}=-270000$, camouflage cost in noncompliance operation $C_{4}=30$, platform compliance operating unit cost $C_{1}=250$, platform market size $L=640$, and penalty after exposure of noncompliant operation $A=3$, we analyze the impact of $E$ on the probability $q^{*}$ of strong supervision by the supervision organization when the additional revenue of noncompliance operation of the platform is $E=2000,2200,2400,2600$ and 2800, respectively. According to formula (4), the corresponding value of $q^{*}$ can be calculated, as shown in Table 8 .

When $\quad R_{2}=1000, \quad R_{3}-R_{1}=-270000, \quad C_{1}=250$, $L=640, C_{4}=30, A=3$, and $E=2000$ are substituted into 
TABLE 6: The influence of $R_{2}$ and $r=\left(R_{3}-R_{1}\right)$ on the probability $q^{*}$ of strong supervision by the supervision organization (take $E=2000$, $L=640, A=3, C_{1}=250$, and $\left.C_{4}=30\right)$.

\begin{tabular}{|c|c|c|c|c|c|}
\hline$q^{*}$ & $R_{2}=1000$ & $R_{2}=1050$ & $R_{2}=1100$ & $R_{2}=1150$ & $R_{2}=1200$ \\
\hline$R_{3}-R_{1}=-270000$ & 0.5177 & 0.5179 & 0.5180 & 0.5182 & 0.5184 \\
\hline$R_{3}-R_{1}=-275000$ & 0.5084 & 0.5086 & 0.5087 & 0.5089 & 0.5091 \\
\hline$R_{3}-R_{1}=-280000$ & 0.4994 & 0.4996 & 0.4998 & 0.5000 & 0.5001 \\
\hline$R_{3}-R_{1}=-285000$ & 0.4908 & 0.4910 & 0.4911 & 0.4913 & 0.4915 \\
\hline$R_{3}-R_{1}=-290000$ & 0.4824 & 0.4826 & 0.4828 & 0.4830 & 0.4831 \\
\hline
\end{tabular}

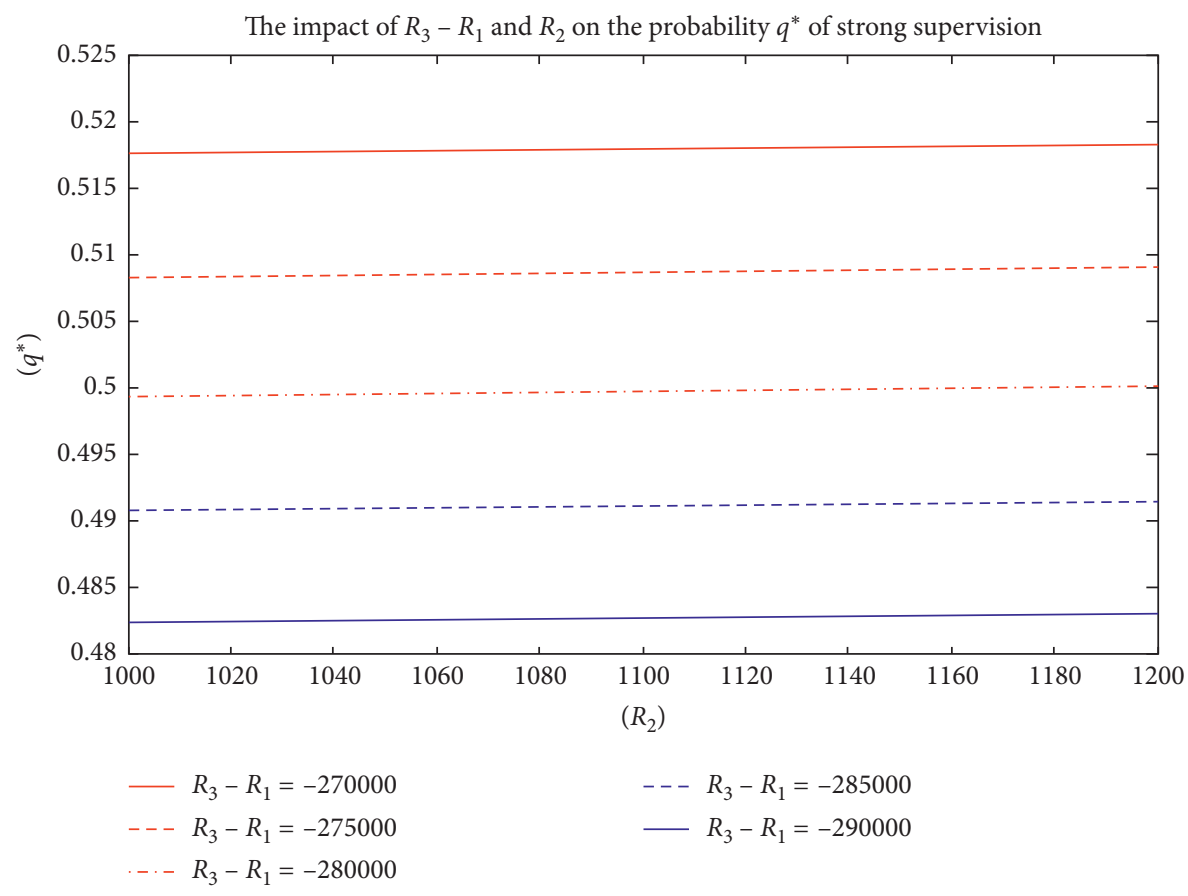

FIGURE 5: The influence of $R_{1}$ and $R_{3}-R_{1}$ on the probability $q^{*}$ of strong supervision by the supervision organization.

TABLE 7: The influence of $L$ and $A$ on the probability $q^{*}$ of strong supervision by the supervision organization (take $E=2000, R_{2}=1150$, $R_{3}-R_{1}=-270000, C_{1}=250$, and $\left.C_{4}=30\right)$.

\begin{tabular}{|c|c|c|c|c|c|}
\hline$q^{*}$ & $L=600$ & $L=620$ & $L=640$ & $L=600$ & $L=680$ \\
\hline$A=3$ & 0.4692 & 0.4846 & 0.5000 & 0.5154 & 0.5307 \\
\hline$A=4$ & 0.4682 & 0.4835 & 0.4988 & 0.5142 & 0.5295 \\
\hline$A=5$ & 0.4672 & 0.4825 & 0.4977 & 0.5130 & 0.5282 \\
\hline$A=6$ & 0.4662 & 0.4814 & 0.4966 & 0.5118 & 0.5270 \\
\hline$A=7$ & 0.4652 & 0.4804 & 0.4955 & 0.5106 & 0.5257 \\
\hline
\end{tabular}

the equilibrium state, the supervision organization determines the expression $q^{*}=\left(\left(C_{3}-C_{2}+A L+E\right) /\left(R_{3}-R_{1}-\right.\right.$ $A L-E)$ ) of the strong supervised probability and it can be found that $q^{*}=0.4692$ (keep 4 decimal places). Other values are calculated using this logic. In order to visualize the table, the value of $E$ is separately taken as $2000,2200,2400,2600$, and 2800, as shown in Figure 7.

As shown in Figure 7, the greater the incentives issued by the government supervision agencies, the more the supervision policies tend to be supervised through market 


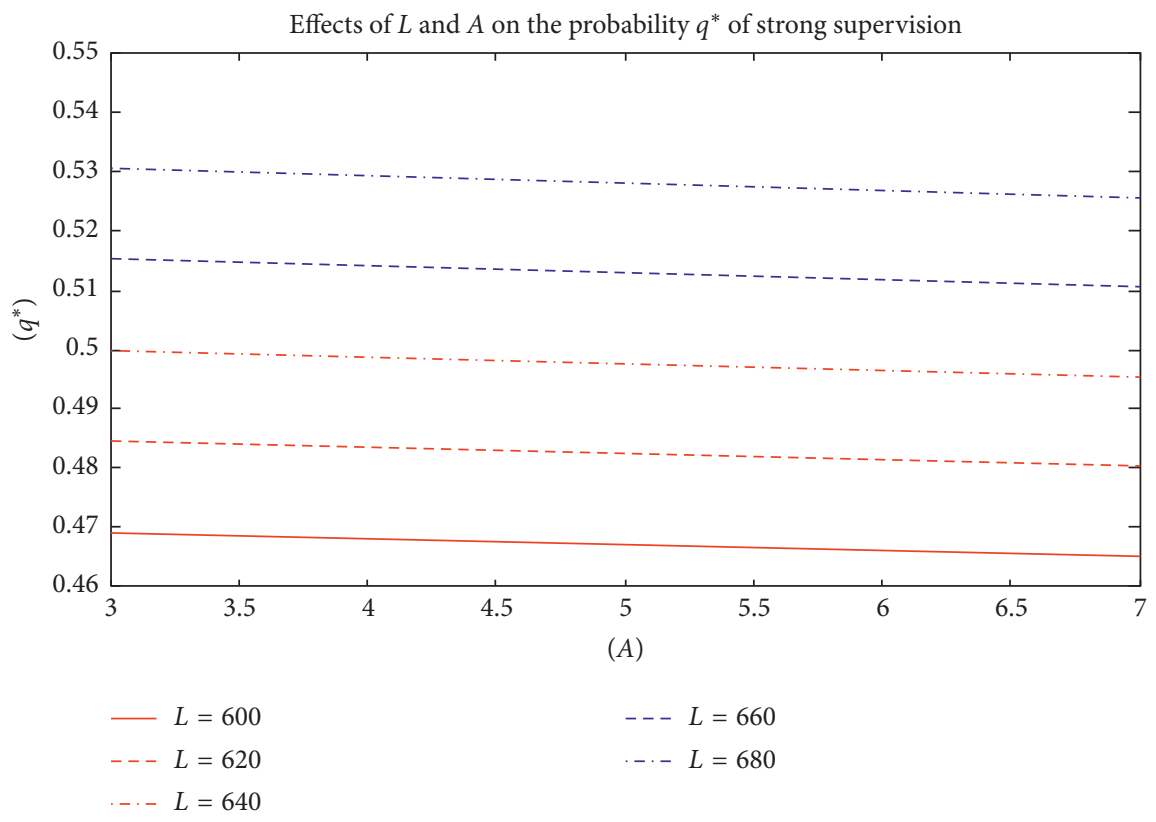

Figure 6: The influence of $L$ and $A$ on the probability $q^{*}$ of strong supervision by the supervision organization.

TABLE 8: The influence of $E$ on the probability $q^{*}$ of strong supervision by the supervision organization (take $R_{2}=1000, R_{3}-R_{1}=-270000$, $C_{1}=250, L=640, C_{4}=30$, and $A=3$ ).

\begin{tabular}{lccccc}
\hline$E$ & 2000 & 2200 & 2400 & 2600 & 2800 \\
\hline$q^{*}$ & 0.5177 & 0.5173 & 0.5169 & 0.5165 & 0.5162 \\
\hline
\end{tabular}

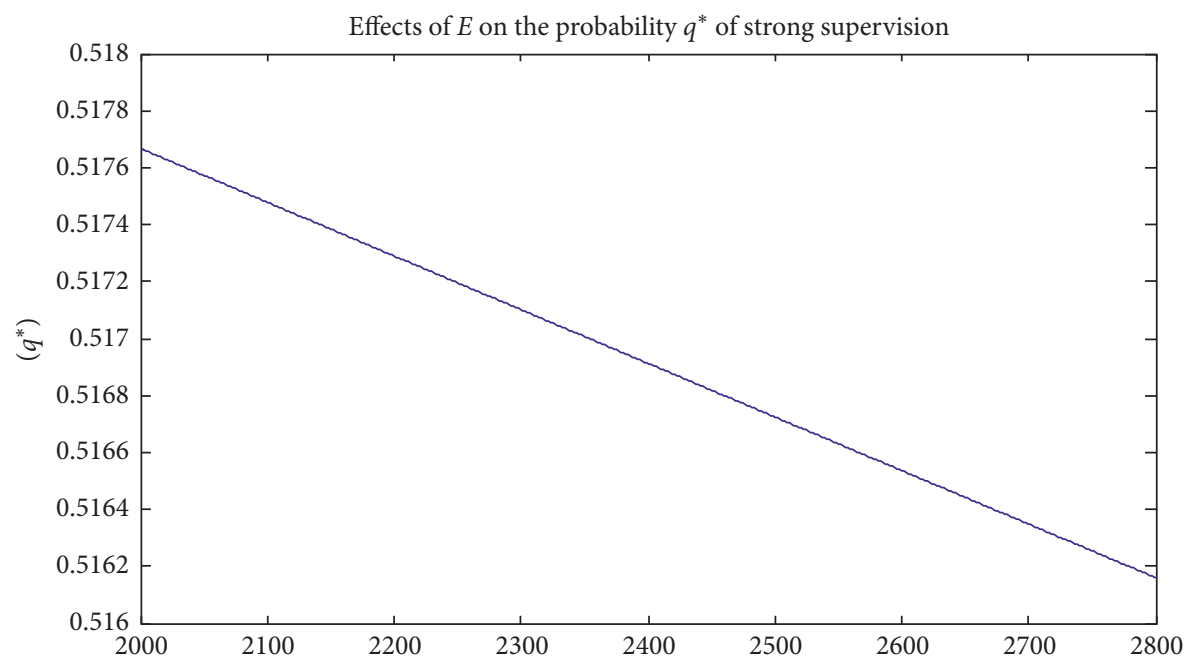

$(E)$

Figure 7: The influence of $E$ on the probability $q^{*} q$ of strong supervision by the supervisory authority.

regulation and platform self-discipline, that is, by issuing greater incentives to promote competition within the industry, the probability of weak supervision will rise.

\section{Conclusions}

This paper analyses a series of supervision policies issued by China in 2015, but because of the complexity of the problem, many supervision policies have not been effectively implemented. Therefore, we use game theory to explore the relationship between the willingness of the P2P lending platform to strengthen supervision and some influencing factors and construct a game model between the platform and financial supervision institutions. We also solve the equilibrium results, analyze, and explain the game results and then provide some suggestions on the behavior choice of 
the P2P lending platform and the supervision organization. We draw the following conclusions:

(1) In the equilibrium state, the P2P lending platform conducts compliance management with a probability of $p^{*}=\left(\left(\left(C_{3}-C_{2}+A\right) L+E\right) / A L\right)$ and the supervision organization conducts strong supervision with the probability of $q^{*}=\left(\left(C_{3}-C_{2}+A L+E\right) /\right.$ $\left.\left(R_{3}-R_{1}-A L-E\right)\right)$.

(2) In the nonequilibrium state, if the P2P lending platform chooses the probability of compliance management $p<\left(\left(\left(C_{3}-C_{2}+A\right) L+E\right) / A L\right)$, the $\mathrm{P} 2 \mathrm{P}$ lending platform will choose noncompliant management. When the supervision organization chooses that there is little difference between strong supervision and weak supervision, the supervision organization chooses strong supervision. When the supervision organization chooses that the difference between strong supervision and weak supervision is relatively large, in order to save supervision costs, the supervision organization will choose weak supervision. If the P2P lending platform chooses the probability of compliance management $p>\left(\left(\left(C_{3}-C_{2}+A\right) L+E\right) / A L\right)$, the P2P lending platform will choose to operate in compliance. At this time, the supervision organization will choose weak supervision to reduce the supervision cost.

(3) In the nonequilibrium state, if the supervision organization chooses the probability of strong supervision $q<\left(\left(C_{4} L-C_{1} L-R_{2}\right) /\left(R_{3}-R_{1}-A L-E\right)\right)$, the supervision organization will choose weak supervision. At this time, the P2P lending platform will choose noncompliant management. If the supervision organization chooses the probability of strong supervision

$q>\left(\left(C_{4} L-C_{1} L-R_{2}\right) /\left(R_{3}-R_{1}-A L-E\right)\right)$, the supervision organization will choose strong supervision. When the supervision organization's incentive for the P2P lending platform is large enough, the P2P lending platform will choose to operate in compliance. When the supervision organization does not have sufficient incentives for the $\mathrm{P} 2 \mathrm{P}$ lending platform, the $\mathrm{P} 2 \mathrm{P}$ lending platform will choose noncompliant management.

(4) The unit fine $A$ paid by the noncompliant P2P lending platform, the size $L$ of the P2P industry platform, and the incentive $E$ of the supervision organization for the compliance platform have certain influence on the probability of supervision organization choosing strong supervision and the decision probability of the platform choosing conforming operation. Among them, when the unit fines paid by noncompliance platforms increase, the probability of choosing compliance platforms will increase in order to avoid the increasing benefits of paying fines, and then, the probability of strong supervision by supervision organizations will decrease. When the scale $L$ of the P2P industry platform increases, the probability of P2P lending platform selecting compliance management will decrease and the supervision organization will increase the probability of strong supervision at this time in order to maintain the stability of the financial order. When the supervision organization's reward $E$ for the compliance platform increases, the supervisory policy is more focused on requiring mutual supervision and competition within the industry. Therefore, the supervision organization will prefer to adopt weak supervision. In order to obtain incentives, the P2P lending platform will increase the probability of conducting compliance operations.

(5) For the P2P lending platform, the unit cost of supervision by the supervision organization and the unit cost of weak supervision are the unique influencing factors that affect the probability of making compliance management decisions. The research in this paper shows that in order to make the $\mathrm{P} 2 \mathrm{P}$ lending platform more willing to make decision-making for compliance management, the supervision organization can reduce or save the unit cost of strong supervision and increase the cost of weak supervision as much as possible; that is, the market feels the existence of a supervision organization.

(6) For the supervision organization, the unit cost of compliant operation of $\mathrm{P} 2 \mathrm{P}$ lending platform, the additional benefits that may be obtained from the platform's noncompliance management, the camouflage cost of noncompliance management, and the loss of reputation when the platform's noncompliance management is investigated and disclosed to the public are the unique factors that influence the decisionmaking of strong supervision by the supervision organization. Through the above analysis, when the unit cost of platform selection for compliance management and the additional income that platform noncompliance management may obtain increase, or the unit fine paid after platform noncompliance management is investigated and punished by the supervision organization, and the loss of reputation and the cost of camouflage are reduced when platform noncompliance management is investigated and punished and publicized to the public. Then, the supervision organization has a greater probability of choosing strong supervision. On the contrary, most supervision organizations will choose weak supervision.

\section{Data Availability}

The data of this paper are obtained from the home of Online Loan. Online Loan home is an open platform. Everyone can access this website to download the data. 


\section{Conflicts of Interest}

The authors declare that they have no conflicts of interest.

\section{Acknowledgments}

This work was supported by the National Natural Science Foundation of China (91646112).

\section{References}

[1] S. Cai, X. Lin, D. Xu, and X. Fu, "Judging online peer-to-peer lending behavior: a comparison of first-time and repeated borrowing requests," Information \& Management, vol. 53, no. 7, pp. 857-867, 2016.

[2] H. Wang, K. Chen, W. Zhu, and Z. Song, "A process model on P2P lending," Financial Innovation, vol. 1, p. 3, 2015.

[3] F. J. Riggins and D. M. Weber, "Information asymmetries and identification bias in P2P social microlending," Information Technology for Development, vol. 23, no. 1, pp. 107-126, 2017.

[4] O. Havrylchyk and M. Verdier, "The financial intermediation role of the P2P lending platforms," Comparative Economic Studies, vol. 60, no. 1, pp. 115-130, 2018.

[5] F. Lehrieder, G. Dan, T. Hossfeld, S. Oechsner, and V. Singeorzan, "Caching for BitTorrent-Like P2P systems: a simple fluid model and its implications," IEEE/ACM Transactions on Networking, vol. 20, no. 4, pp. 1176-1189, 2012.

[6] D. ManojPrasadh, N. Hemachandar, R. A. Karthik, and C. R. Chandrasekaran, "BCOS EPL: building co-operative systems for extending peer to peer system lifetime," in Proceedings of the 2009 International Conference on Signal Processing Systems, pp. 215-218, Singapore, May 2009.

[7] J. Li, S. Hsu, Z. Chen, and Y. Chen, "Risks of P2P lending platforms in China: modeling failure using a cox hazard model," The Chinese Economy, vol. 49, no. 3, pp. 161-172, 2016.

[8] G. Chen, "Research on crisis perception model of P2P network lending platform," AER-Advances in Engineering Research, Atlantis Press, Amsterdam, Netherlands, pp. 72-75, 2016.

[9] Y. Zhang, H. Jia, Y. Diao, M. Hai, and H. Li, "Research on credit scoring by fusing social media information in online peer-to-peer lending," Procedia Computer Science, vol. 91, pp. 168-174, 2016.

[10] J. Yan, K. Wang, Y. Liu et al., "Mining social lending motivations for loan project recommendations," Expert Systems with Applications, vol. 111, pp. 100-106, 2018.

[11] E. V. Tassel, "Group lending under asymmetric information," Journal of Development Economics, vol. 60, no. 1, pp. 3-25, 1999.

[12] G.-X. Gao, Z.-P. Fan, X. Fang, and Y. F. Lim, "Optimal Stackelberg strategies for financing a supply chain through online peer-to-peer lending," European Journal of Operational Research, vol. 267, no. 2, pp. 585-597, 2018.

[13] J. J. Xu and M. Chau, "Cheap talk? The impact of lenderborrower communication on peer-to-peer lending outcomes," Journal of Management Information Systems, vol. 35, no. 1, pp. 53-85, 2018.

[14] R. Ge, J. Feng, B. Gu, and P. Zhang, "Predicting and deterring default with social media information in peer-to-peer lending," Journal of Management Information Systems, vol. 34, no. 2, pp. 401-424, 2017.

[15] J. Feller, R. Gleasure, and S. Treacy, "Information sharing and user behavior in internet-enabled peer-to-peer lending systems: an empirical study," Journal of Information Technology, vol. 32, no. 2, pp. 127-146, 2017.

[16] C. Serrano-Cinca and B. Gutiérrez-Nieto, "The use of profit scoring as an alternative to credit scoring systems in peer-topeer (P2P) lending," Decision Support Systems, vol. 89, no. 6, pp. 113-122, 2016.

[17] C. Jiang, Z. Wang, R. Wang, and Y. Ding, "Loan default prediction by combining soft information extracted from descriptive text in online peer-to-peer lending," Annals of Operations Research, vol. 266, no. 1-2, pp. 511-529, 2018.

[18] J. Michels, "Do unverifiable disclosures matter? Evidence from peer-to-peer lending," The Accounting Review, vol. 87, no. 4, pp. 1385-1413, 2012.

[19] Y. Li, A. Hao, X. Zhang, and X. Xiong, "Network topology and systemic risk in peer-to-peer lending market," Physica A: Statistical Mechanics and Its Applications, vol. 508, no. 5, pp. 118-130, 2018.

[20] G. Dorfleitner, C. Priberny, S. Schuster et al., "Descriptiontext related soft information in peer-to-peer lending-evidence from two leading European platforms," Journal of Banking \& Finance, vol. 64, no. 3, pp. 169-187, 2016.

[21] A. Mild, M. Waitz, and J. Wöckl, "How low can you go?Overcoming the inability of lenders to set proper interest rates on unsecured peer-to-peer lending markets," Journal of Business Research, vol. 68, no. 6, pp. 1291-1305, 2015.

[22] L. Larrimore, L. Jiang, J. Larrimore, D. Markowitz, and S. Gorski, "Peer to peer lending: the relationship between language features, trustworthiness, and persuasion success," Journal of Applied Communication Research, vol. 39, no. 1, pp. 19-37, 2011.

[23] E. Kohlberg and A. Neyman, "Games of threats," Games and Economic Behavior, vol. 108, pp. 139-145, 2018.

[24] H. P. Young, "Commentary: John Nash and evolutionary game theory," Games and Economic Behavior, vol. 71, no. 1, pp. 12-13, 2011. 